\title{
Measurement of the lower canine pulp chamber through periapical radiography for age estimation
}

\author{
Otty Ratna Wahyuni ${ }^{*}$, Deny Saputra', Nastiti Faradilla Ramadhani', Dennaya Listya Dias²
}

\begin{abstract}
Objectives: The principle of measurement using the $\mathrm{TCl}$ (Tooth Coronal Index) method is to compare the pulp chamber height with a person's chronological age based on the formation of secondary dentin. The purpose of this study is to estimate age based on pulp chamber height in lower canines using periapical radiographs with $\mathrm{TCl}$ measurement.
\end{abstract}

Materials and Methods: This study is an observational analytic study using 42 samples of periapical radiographs with the parallel technique of the lower canines. Samples were measured for $\mathrm{CH}$ and $\mathrm{CPCH}$ heights to determine $\mathrm{TCl}$ values and

${ }^{1}$ Department of Dentomaxillofacial Radiology, Faculty of Dental Medicine, Universitas Airlangga, Surabaya, Indonesia, 60132

${ }^{2}$ Undergraduate Student, Faculty of Dental Medicine, Universitas Airlangga, Surabaya, Indonesia, 60132

"Correspondence to:

Otty Ratna Wahyun

囚otty-r-w@fkg.unair.ac.id

Received on: June 202 Revised on: July 2021

Accepted on: August 2021 then linear regression was made to determine their biological age. Finally, the difference between biological and chronological age is calculated to determine the approximate age.

Results: The mean difference between chronological age and biological age was \pm 5.05 years and an average biological age of 29.38 years.

Conclusion: TCl method based on pulp chamber height in lower canines using periapical radiographs can be used to estimate age with the difference between chronological age and biological age of about \pm 5.05 years.

Keywords: Age estimation, lower canines, periapical radiography, Tooth Coronal Index

Cite this article: Wahyuni OR, Saputra D, Ramadhani NF, Dias DL. Measurement of the lower canine pulp chamber through periapical radiography for age estimation. Jurnal Radiologi Dentomaksilofasial Indonesia 2021;5(2)48-51. https://doi.org/10.32793/jrdi.v5i2.710

\section{INTRODUCTION}

A person's age may describe the individual's life. In the process of identifying an unrecognized body in forensics, especially if only some body parts remain, especially teeth and skeleton, forensic odontologists may perform age estimation to help identification. ${ }^{1}$ Age estimation is one of the important steps in identifying deceased humans. ${ }^{2}$ Various parts of the body may be analyzed to estimate a person's age, but in severe cases such as in burned victims or victims who recently died, it is likely impossible to conduct the identification analysis using any body parts. This reason causes teeth to be the most frequently used body parts for identification and estimation of age. ${ }^{3}$

Age estimation using the radiographic analysis is a non-invasive method. There are several methods for age estimation using radiographic analysis, such as Tooth Coronal Index ( $\mathrm{TCl}$ ) method. The principle of measurement using the $\mathrm{TCl}$ method is to compare the pulp chamber height with a person's chronological age. Parameters for determining age were pulp chamber size which indicated the formation of secondary dentin with increasing age. ${ }^{4}$

Radiography has an important meaning in forensic odontology because with the help of radiographs, it can help to reveal hidden facts that are not visible only by physical examination alone.
The radiography technique used in this study was periapical intraoral radiography. The periapical radiography technique is used because it can show the condition of the teeth and supporting bones clearly and the distortion is very minimal. ${ }^{5}$

Canines are more durable compared to other teeth, as they do not depend on age and are rarely used in mastication than other teeth. The lower canines were found to have the biggest pulp chamber compared to other single root mandibular teeth in previous study. ${ }^{6}$ In a study conducted by Nawaya (2016) in Damascus, the TCl method can be performed on incisors, canines, premolars, first molars and second molars. ${ }^{7}$

According to that, it is necessary to conduct a study to estimate age based on pulp chamber height in lower canines with the TCl method. This research was conducted using periapical radiography at the Dental Radiology Department, Universitas Airlangga Dental Hospital Surabaya, which had never been done before.

\section{MATERIALS AND METHODS}

This research was conducted at the Integrated Specialistic Clinic of Universitas Airlangga Dental 
Hospital Surabaya. The research samples were 42 periapical radiographs with criteria for age between 14 - 50 years, the amount of 42 samples and periapical radiographs had good quality evaluation.

Radiograph were observed by 3 observers on the periapical radiograph of the lower canines using the $\mathrm{TCl}$ method. The tooth length measurement in this research were divided into 2 parts following TC guideline, as shown in Figure 1. The first step is to calculate the Coronal Height $(\mathrm{CH})$ of the tooth which is measured vertically from the Cementoenamel Junction (CEJ) to the peak point of the highest cusp of the crown. The second assessment is to calculate the Coronal Pulp Cavity Height ( $\mathrm{CPCH}$ ) which is measured vertically from the CEJ to the peak point of the highest pulp horn. This measurement were measured by using a digita caliper (Frederer) with an accuracy of $0.01 \mathrm{~mm}$ The final value of age estimation was obtained by entering the previous measurement results within the $\mathrm{TCl}$ provided formula, as shown in Figure 2.

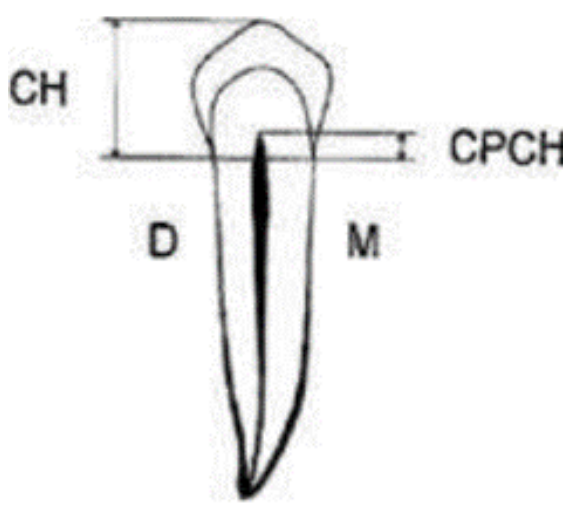

Figure 1. Description of $\mathrm{CPCH}$ and $\mathrm{CH}^{8}$

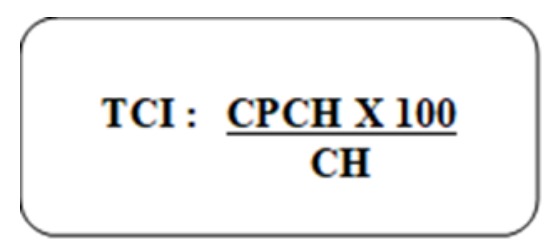

Figure 2. TCI Formula
All data from 42 samples was then analyzed with SPSS Version 17.0 for Microsoft (IBM Corp, Chicago, USA). The normality test of the data was measured with Kolmogrov - Smirnov test. Homogeneity test of variance by Levene Statistics and paired t-test were done at 0.05 significance to find any difference between groups.

\section{RESULTS}

The final result was shown in Table 1 and 2. In Table 1, the average age difference is obtained from the calculation of the difference between each sample in the average difference in biological and chronological age. The difference is obtained from linear regression analysis with least square test between age and the average $\mathrm{TCl}$ of the lower canines by the average of the three observers, so that the estimation equation is obtained:

\section{$Y=32,96-0,07$ (AVERAGE TCI)}

The equation is then substituted to the results of the average $\mathrm{TCl}$ calculation to determine the biological age, which is then compared with the chronological age to assess the difference between them.

Table 2 showed that the P-value is 0.978 , which means that the P-value for this result is $>0.05$. Thus, it can be summarized that there is no significant difference between the biological age and the chronological age in age estimation using lower canine.

\section{DISCUSSION}

In this study, we found that age estimation based on the pulp chamber height of the lower canines resulted the mean difference between chronological age and biological age which was \pm 5.05 years. Factors that can affect the difference in

Table 1. Mean \pm SD and $p$ value between groups

\begin{tabular}{cccc}
\hline $\begin{array}{c}\text { NUMBER OF } \\
\text { SAMPLES (N) }\end{array}$ & $\begin{array}{c}\text { AVERAGE } \\
\text { BIOLOGICAL AGE }\end{array}$ & $\begin{array}{c}\text { AVERAGE } \\
\text { CHRONOLOGICAL AGE }\end{array}$ & $\begin{array}{c}\text { AVERAGE } \\
\text { AGE DIFFERENCE }\end{array}$ \\
\hline 42 & 29,38 & 29,4 & 5,05 \\
\hline
\end{tabular}

Table 2. Paired T-Test chronological and biological age

\begin{tabular}{ccc}
\hline N & CORRELATION & P-VALUE \\
\hline 42 & 0,105 & 0,978 \\
\hline
\end{tabular}


age estimates include variations in tooth morphology and variations in secondary dentin deposits between each person, and biased images resulting from the patient's position or X-rays. ${ }^{9}$ It also occurs due to external factors which have been shown to influence bone growth processes in older adults, such as differences between nutrition, disease, lifestyle and socio-economic status for individuals. All of this factors, both internal and external factors can interact and affect the results of the age estimation. ${ }^{10}$

In this study, the parallel technique was used to reduce image distortion by placing the film parallel to the tooth axis and the direction of the beam perpendicular to the film. ${ }^{11}$ The anatomical shape of the lower canine root which is conical but slenderer than the upper canine root, which is usually convex on the lingual surface and narrower mesiodistally, causes a difference in the height of the cervical line, and affects the CEJ on the lingual and facial sections so that there is a difference. This is consistent with previous research which stated that there are significant differences in the lingual and facial CEJ on periapical radiographs with parallel technique. ${ }^{12,13}$

A previous study conducted by Cameriere had a difference in the mean age for the upper and lower canines, namely, \pm 4.74 years for the upper canines, and \pm 4.47 years for the lower canines. ${ }^{14}$ In another study, Cameriere found that the age estimates have a mean age difference ranging between 4.34 and 6.02 and it is believed that an age estimation error equal to or below than 10 years can still be considered for use in estimating age. ${ }^{15}$ This indicates that the mandibular canines can be used as an indicator for the estimation of a person's age. Canines were used less for mastication process so that they are expected to be intact until old age, and had the largest pulp chamber compared to other single root teeth, making them easier to use for age estimation using radiographic analysis especially in $\mathrm{TCl}$ method. ${ }^{16}$

In this study, the correlation between the height of the coronal pulp cavity and the chronological age was significant which indicates a negative correlation among $\mathrm{TCl}$ value and chronological age. It was also similar to previous studies conducted in Malawi and Western Australia. ${ }^{4,8}$ These findings suggest that the height of the pulp chamber decreases with age. As a result, the $\mathrm{TCl}$ value decreases with increasing age. $^{17}$

There is no significant difference between chronological and biological age at each age, indicating that this method can be used in any age group. This study is expected to provide information in the fields of radiology and forensic odontology that the reduction in pulp size seen through periapical radiographs on the lower canines shows an estimated age of a person's that can be used for identification.

\section{CONCLUSION}

Based on the results of this study, it is reasonable to conclude that the $\mathrm{TCl}$ method based on the height of the pulp in lower canines using periapical radiographs can be used to estimate age with the difference between chronological age and biological age of about \pm 5.05 years, and also with the average of biological age is 29.38 years.

\section{ACKNOWLEDGMENTS}

None.

\section{FOOTNOTES}

All authors have no potential conflict of interest to declare for this article. This research was registered and approved by Health Research Ethical Clearance Commission (HRECC) Faculty of Dental Medicine Universitas Airlangga Surabaya with the registration number of 083/HRECC.FODM/VII/2018. All procedures conducted were in accordance with the ethical standards.

\section{REFERENCES}

1. Priyadarshini C, Puranik MP, Rajagopalachari US. Dental Age Estimation Methods-A Review. LAP Lambert Academic Publishing; 2015

2. Singaraju $S$, Sharada P. Age estimation using pulp/tooth area ratio: A digital image analysis. Journal of Forensic Denta Sciences. 2009;1(1): 37-41.

3. Saxena S. Age estimation of indian adults from orthopantomographs. Braz Oral Res. 2011;25(3):225-9.

4. Drusini AG. The coronal pulp cavity index: A forensic tool for age determination in human adults. Cuad Med Forense. 2008;14(53):235-49.

5. Whaites E. Essentials of Dental Radiology and Radiography. 4th ed. Churchill: Elsevier; 2007. p.91, 113, 125-30, 209-14.

6. De Angelis D, Gaudio D, Guercini N, Cipriani F, Gibelli D, Caput $\mathrm{S}$, et al. Age estimation from canine volumes. Radiol med. 2015;120:731-6

7. Nawaya FR, Burhan AS. Use of the Tooth Coronal Pulp Index for Recognition of the Pubertal Growth Period. J Contemp Dent Pract. 2016;17(11):884-9.

8. Igbigbi PS, Nyirenda SK. Age estimation of Malawian adults from dental radiographs. West Afr J Med. 2005;24(4):329-33.

9. Azevedo Ade C, Alves NZ, Michel-Crosato E, Rocha M, Cameriere R, Biazevic MG. Dental age estimation in a Brazilian adult population using Cameriere's method. Braz Oral Res. 2015;29:S1806-83242015000100215

10. Jackes M. Building the bases for paleodemographic analysis: adult age determination. In: Katzenberg, M.A., Saunders, S.R. (Eds.), Biological Anthropology of the Human Skeleton. New York: Wiley-Liss, Inc.; 2000. p.417e466

11. White SC, Pharoah MJ. Oral radiology: Principles and interpretation. 7th ed. St. Louis: Mosby/Elsevier; 2014.

12. Woelfel JB, Scheid RC, Weiss G. Woelfel's dental anatomy Philadelphia: Wolters Kluwer Lippincott Williams \& Wilkins; 2012.

13. Brezniak N, Goren S, Zoizner R, Shochat $T$, Dinbar A, Wasserstein A, Heller M. The accuracy of the cementoename junction identification on periapical films. Angle Orthod. $2004 ; 74(4): 496-500$

14. Cameriere R, Ferrante L, Belcastro MG, Bonfiglioli B, Rastelli $E$ Cingolani M. Age estimation by pulp/tooth ratio in canines by mesial and vestibular peri-apical X-rays. J Forensic Sci. 2007;52 (5):1151-5.

15. Cameriere R, De Luca S, Alemán I, Ferrante L, Cingolani M. Age estimation by pulp/tooth ratio in lower premolars by 
orthopantomography. Forensic Sci Int. 2012;214(1-3):105-12.

16. Jagannathan $N$, Neelakantan $P$, Thiruvengadam $C$, Ramani $P$, Premkumar P, Natesan A, Herald JS, Luder HU. Age estimation in an Indian population using pulp/tooth volume ratio of mandibular canines obtained from cone beam computed tomography. J Forensic Odontostomatol. 2011;29(1):1-6.

17. Nagi R, Jain S, Agrawal P, Prasad S, Tiwari S, Naidu GS. Tooth coronal index: Key for age estimation on digital panoramic radiographs. J Indian Acad Oral Med Radiol 2018;30:64-7. 